LA-UR- $93-1872$
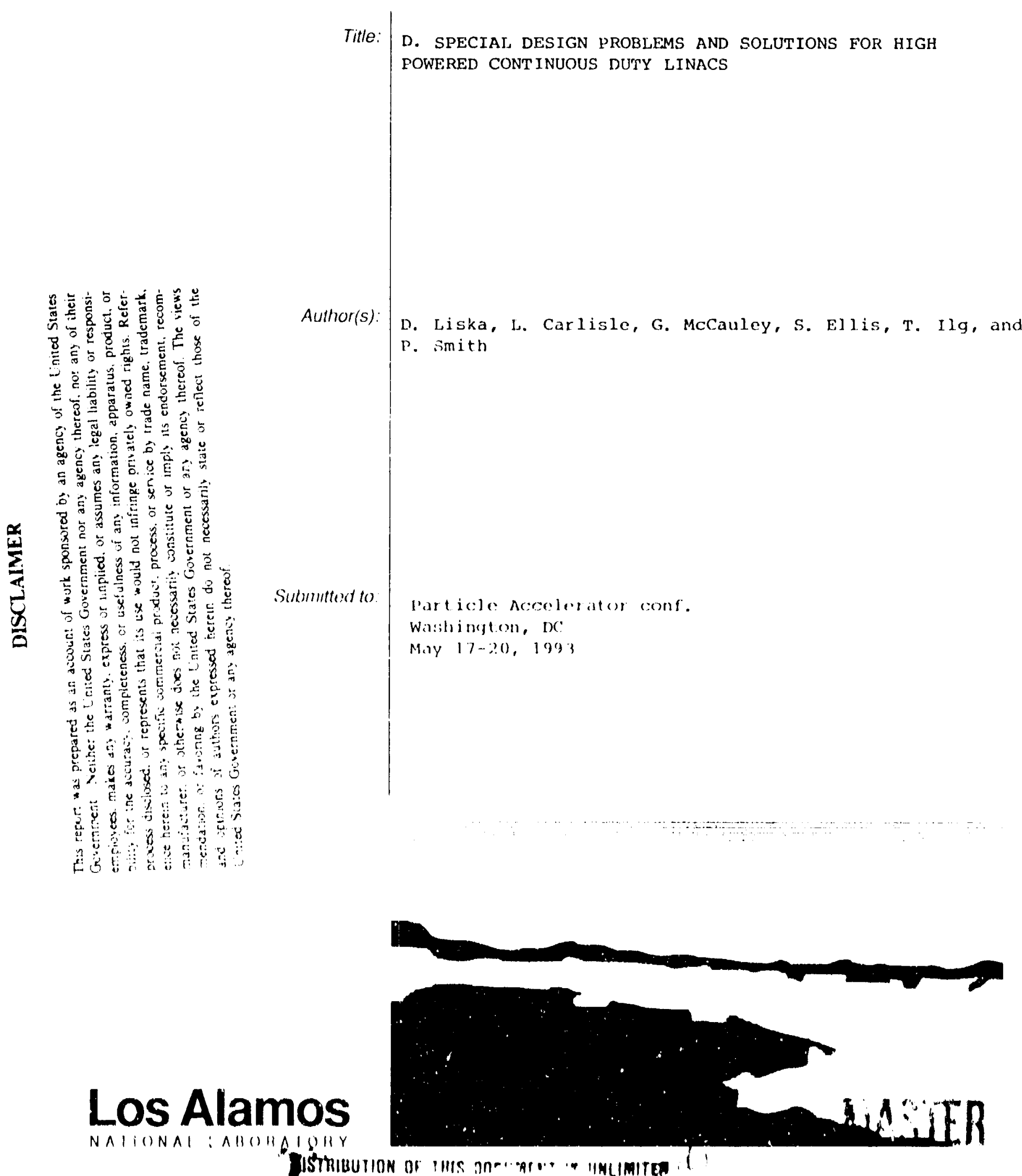

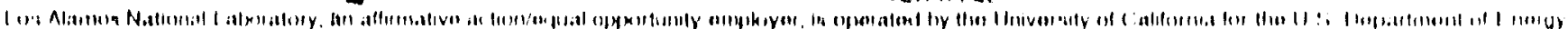

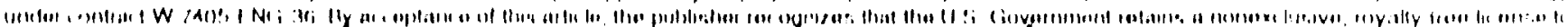

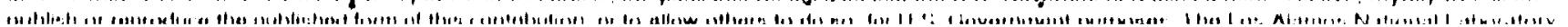




\title{
SPECIAL DESIGN PROBLEMS AND SOLUTIONS FOR HIGH POWERED CONTINUOUS DUTY LINACS*
}

\author{
D. L.iska, L. Carlisle, and G. McCauley \\ Los Alamos National Laboratory \\ P.O. Box 1663, Los Alamos, NM 87545 USA \\ S. Ellis, T. Ilg and P. Smith \\ Grumman Acrospace. \\ Bethpage, New York 11714
}

\section{Abstract}

Several high powered linac designs are heing considered for various purposes including radioactive waste treatment, tritium production, and neutron factorics for materials studies. Since the tractional beam losses must be in the $10^{-5}$ to $10^{-6}$ range and are clearly subject to operational variables, the design engineers are forced to develop concepts which combine maimtainability under radioactivity conditions, high availability, and very high reliability while dealing with the operating paraneters resulting from ( $W$ operation. Several design solutions on selected problems are oresented.

\section{INTROIDUCTION}

A common feature of the new class of high powered linacs being considered for such futurc lasks as radioaciove wasle Iransmulation, plutonium neutralization, tritiom production, etce is the unprecedented power carried in the lxam. A lypical design for a 1 (ieV proton linac at $200 \mathrm{~mA}$ implies a beam power of $2(x)$ megawatts ( $W$ ! An impertant lask in designing such a lonac is to sifleguatd the boretule from beam impingment by configuring tine machine with a

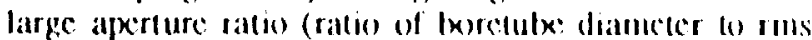
Ix:am diancter). This involves the use of shont focussing: lattices to tightly contan the beam, domble foreussing.

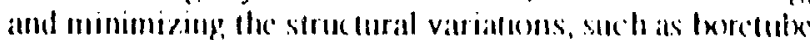
diameter on lantice length changes. $\wedge$ scoond lask in

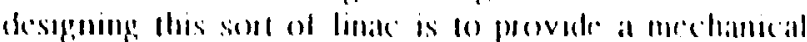

design which recognizes the major areas of potential operational difficulties such as multipactoring, RF and vacuum seal integrity, cooling channel durability and corrosion resistance as well as areas requiring relatively high maintenance so that accessibility and speed of maintenance in radioactive environments can to properly addresised.

\section{Ii. 'THE AP'T POINT DESIGN AT IOS ALAMOS}

Shown in ligg. I is a block diagram of the los Aiamos design for a high power linac. The same machine, or one closely related to it can bx used for waste treatment (ATW) or conversion of plutonium (ABC). Wo call machines of this type $\wedge \times Y$ linass. The linas is heavily bearn loaded (79\%) and will consume alxout 470 MVA (o) operate. It consists of (wo $l(x) m A \|^{+}$injector lanes feeding a funnel all 2() $\mathrm{Mc} V$ which combines the $(w 0)$ beams. The frequency of operation of the RIQ and istl 's in the injector lines is $350 \mathrm{MHz}$ and downstream of the funnel the $2(x) m A$ bealu is accelerated by $\mathrm{Rl}$ : structures operating, at $7(x) \mathrm{MH} \%$. Beyond the funnel the aperture ratio is gradlually increased through the Bridge coupled

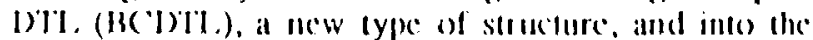

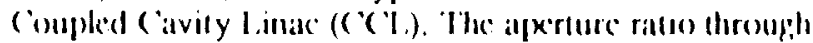
the (') Which comprises the buik of the machine

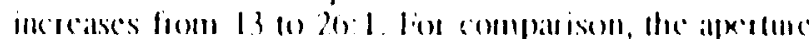

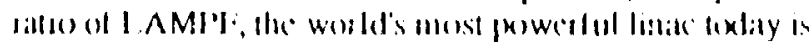
only $(1: 1$

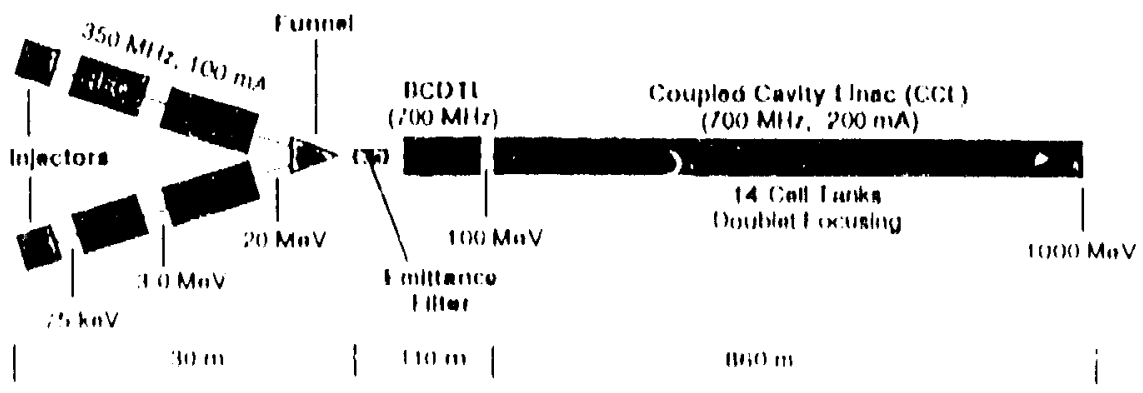

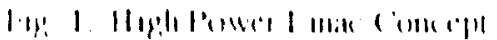

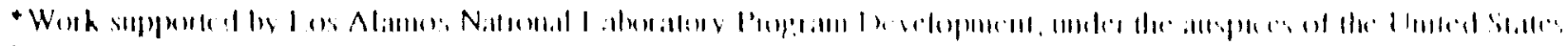

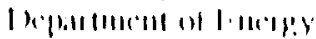




\section{ENGINELERING SOLUTIONS DEVELOPED IN THE APT DESIGN FOR HIGH POWERED STRUCTURES:}

\section{A) Innovitive Accelerating Structures}

In order to be able to use EMQ's in the DTLs, a high energy RFQ was required. A design was developed for a multi-sectioned RFQ to operate at $7 \mathrm{MeV}$ (ref. 1). This 8 meter long unit actually functions as four independent 2 meter long RFQs thereby avoiding mode interterence problems.

The other new structure is the BCD'L which is a multuple tank DTL, with quadrupole doublet focussing in the intertank spaces much like a bridge coupled CCL. The BCDTL, has large apertures at high frequency anci solves many abrication and eperational problems associated with $\mathrm{CCl}$ s at low energy (rels. 2 \& 3 ).

\section{B) Radiation Ilardening}

Because of the potential for neutron damage to materials, essentially all the quadrupoles in the ATW point design are EMQ's with radiation resistant poting of the field coils. The lechnique proposed is shown in Fig. 2a-c. The coils are coated with a glass frit compound, firced to produce a glass conted surface and then potted in calcium aluminate cement (ref 4). In additiot., yuads are designed with demountable vokes so the coils can in removed if necessistry

Radiation hardening of the vacumu scals and knife. edge style RF seals are cosential in all A'T lype machine. We used the Helicollex seat for most vacuum closures. Most of the Helicoflex fxamline scals are used in conjenction with Helicoflex Quick filanges which call the released and sealed from the aiske side of the manhe with a single air drive serew. Thassure high Rl maghi. v. the $\mathrm{Rl}$ jomts throughout most of the madhine are kull: edges using a moxlified conllat concept baked up by an independent Helicentex seal conclosed m the salme Hangec pair (lig. 3).

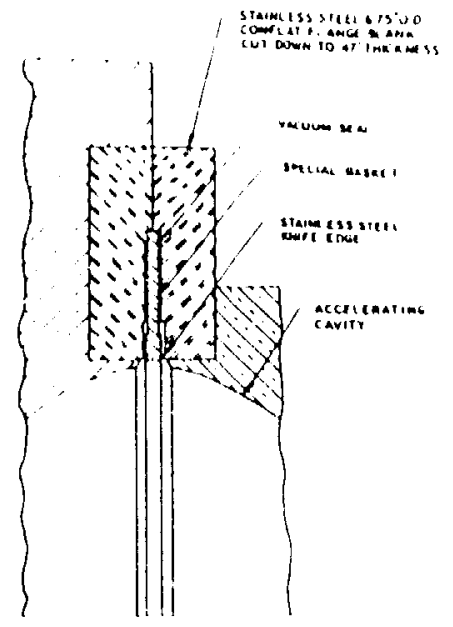

Fig. 3. Flange 1)esign.

\section{()) Modularization}

ATW is modularized as illustraled in ligg. 4. The

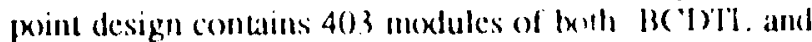
c(I. types reyuiring 360 \& $\mathrm{MW}$ klystrons. Moxdularizatom breaks the linas into manageable length for vacuum checkout and instrumentation. The moxlutes are preassembled in the lab, aligned and checked out for vacuum, cooling and Rli integrity. They art' then tansported to the tunnel and installed on 3 - point suppont mounts and aligned 10 the tunnel alignment system. 1 .'” beamline height is 1.47 meless which makes the molules convenicont to work on. Most essential compentents are accessible from the aiske side, including the items most likely to necel mantenande, i.s. the ion pumps and Ixamulue components such as diapuostic devices lexiled in the intertank spates. ling s shows a typical doublet

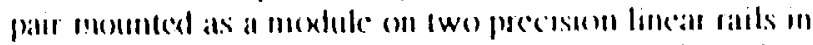
lle interlank falps. biagmostics, bellows, beamlance

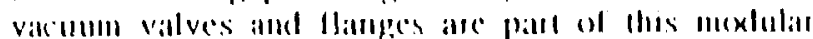

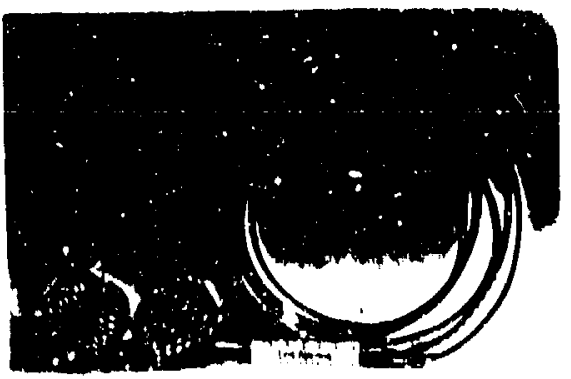

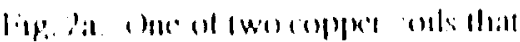

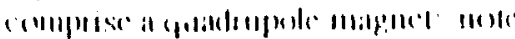

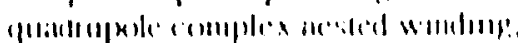

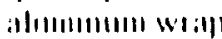

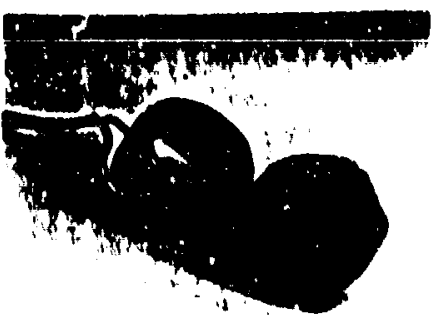

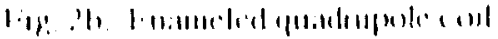

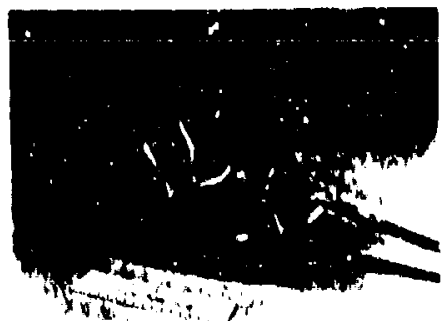

$-$

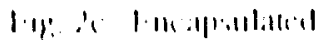
(in) 


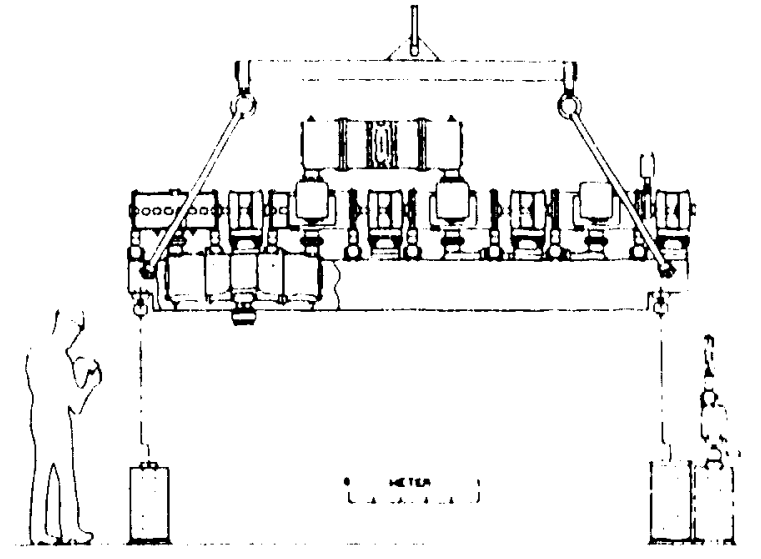

Fig. 4. Modular I inac Design.

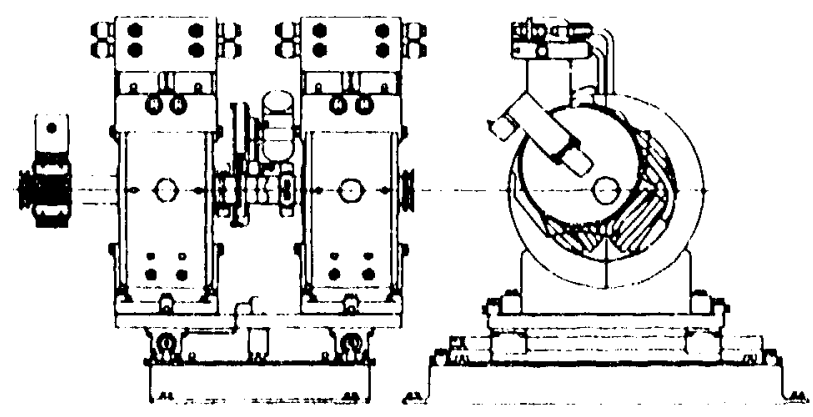

Iry. 5. Moxlular I onuhled

assembly. The doublet patt is critically allended telative

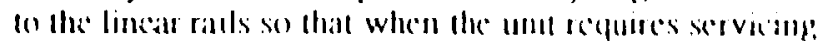
il can le removed casily and encunted onl a smalat sed of

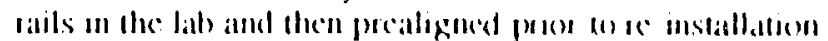

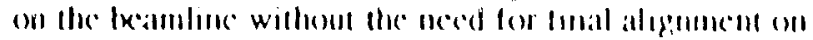
lince.

1) Compronenc comsaderalioms

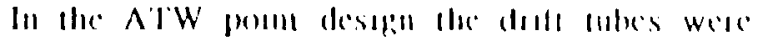

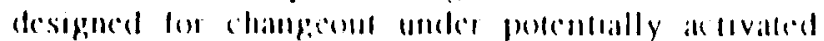

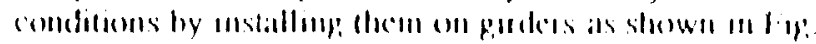

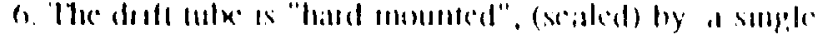

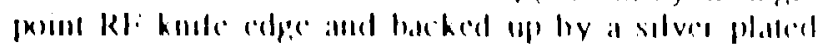

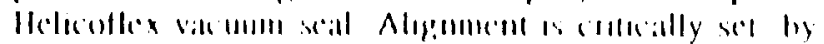

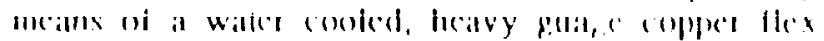

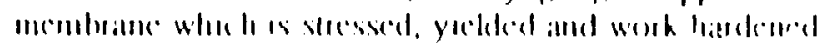

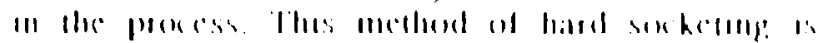

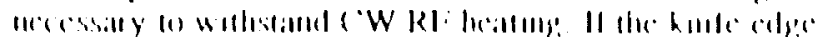

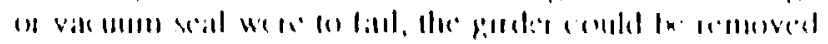

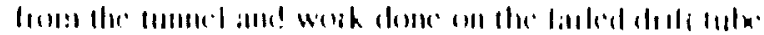

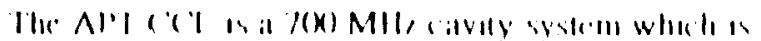

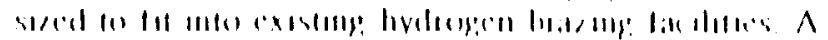

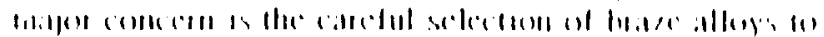

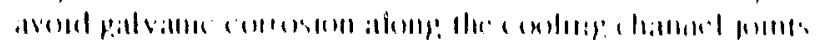

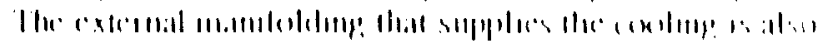

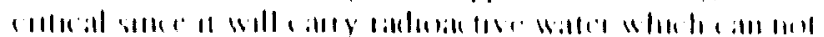

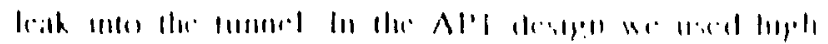

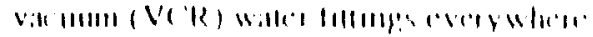

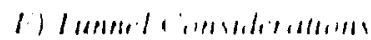

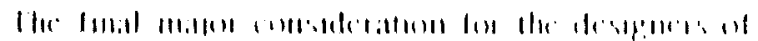

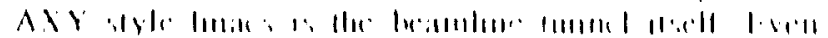

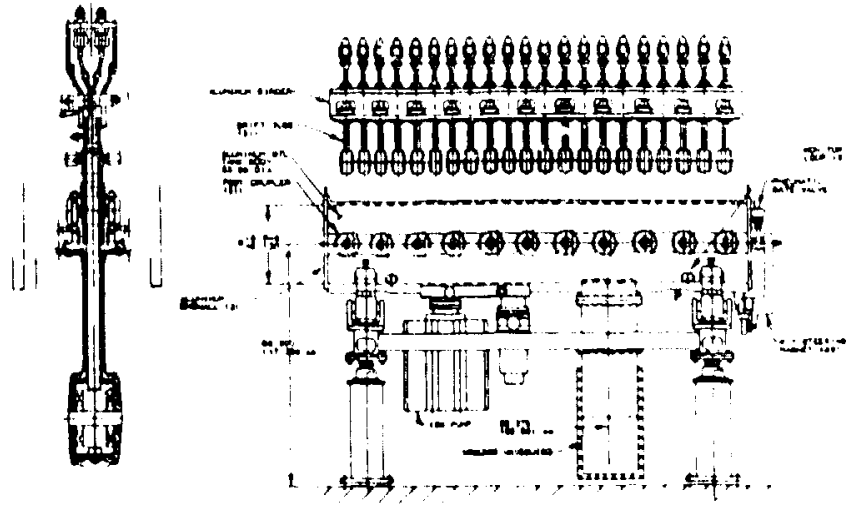

Figh. 6. (iirder Mounted I)rift I ule's

lhough any given desiga will always assime hands-on mantenance as the design goal and the physics will always maximize such parameters as "aperture ratio", one must always consider future changes in personnel exposure limits, abrormal operation of the machine or degrabation. For these reasons it is wise to allow for the possibility of remote manrenance. 'fwo major features are incorporated in our Al'W prone design. (net is the use of radio controlled bridge crances in the llunsel to carry surveillance booms as an adjunct to the normal workhorse linnetion. The oflee leature is a lunnel spacious emongh lo allow a high performance remole matutchance master slave servo manipulator system fo work. () on swh system is MANTIS, used at (TERN.

\section{IV. ( Y INCIIISII:NS}

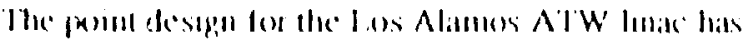

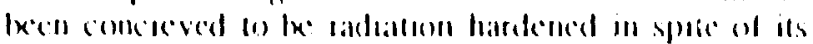

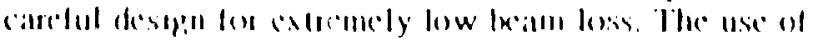

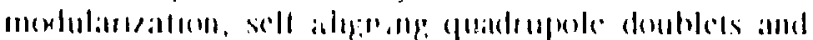

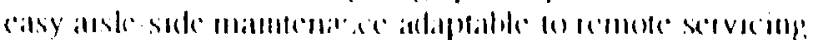

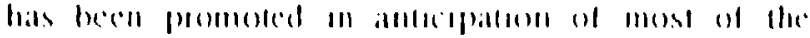

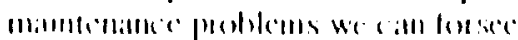

\section{RIIIIRI:NOTSS}

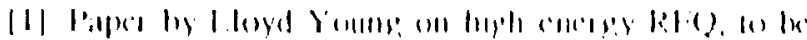

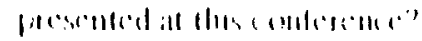

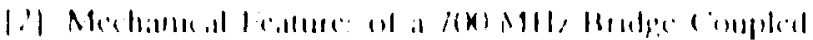

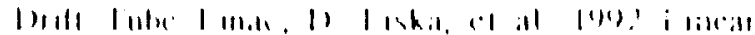

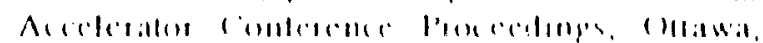

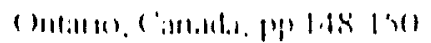

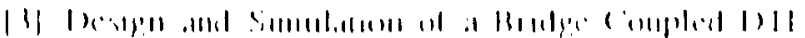

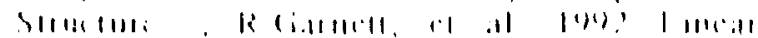

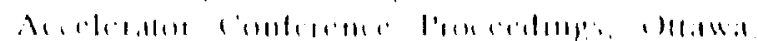

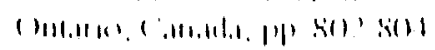

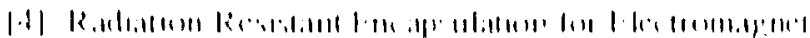

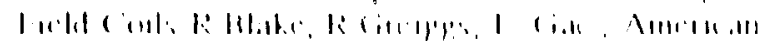

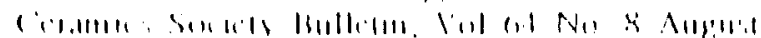
linis 